\title{
Cognitive rehabilitation of episodic memory disorders: from theory to practice
}

\author{
Radek Ptak ${ }^{1,2 *}$, Martial Van der Linden ${ }^{3}$ and Armin Schnider ${ }^{1,2}$ \\ Department of Clinical Neurosciences, Division of Neurorehabilitation, University Hospitals Geneva, Geneva, Switzerland \\ 2 Faculty of Medicine, University of Geneva, Geneva, Switzerland \\ ${ }^{3}$ Faculty of Psychology and Educational Sciences, University of Geneva, Geneva, Switzerland
}

\section{Edited by:}

Brian Levine,

University of Toronto, Canada

\section{Reviewed by:}

Eva Svoboda, Baycrest, Canada Jessica Fish, University of Cambridge, UK

\section{${ }^{*}$ Correspondence:}

Radek Ptak, Department of Clinical

Neurosciences, Division of

Neurorehabilitation, University

Hospitals Geneva, 26, av. de

Beau-Séjour, 1211 Geneva 14,

Switzerland.

e-mail: radek.ptak@hcuge.ch
Memory disorders are among the most frequent and most debilitating cognitive impairments following acquired brain damage. Cognitive remediation strategies attempt to restore lost memory capacity, provide compensatory techniques or teach the use of external memory aids. Memory rehabilitation has strongly been influenced by memory theory, and the interaction between both has stimulated the development of techniques such as spaced retrieval, vanishing cues or errorless learning. These techniques partly rely on implicit memory and therefore enable even patients with dense amnesia to acquire new information. However, knowledge acquired in this way is often strongly domain-specific and inflexible. In addition, individual patients with amnesia respond differently to distinct interventions. The factors underlying these differences have not yet been identified. Behavioral management of memory failures therefore often relies on a careful description of environmental factors and measurement of associated behavioral disorders such as unawareness of memory failures. The current evidence suggests that patients with less severe disorders benefit from self-management techniques and mnemonics whereas rehabilitation of severely amnesic patients should focus on behavior management, the transmission of domain-specific knowledge through implicit memory processes and the compensation for memory deficits with memory aids.

Keywords: memory disorders, episodic memory, amnesia, memory rehabilitation, spaced retrieval, errorless learning, prospective memory, neural plasticity

\section{INTRODUCTION}

Popular literature is full of proposals and promises that memory skills may be enhanced through specific exercises. People commonly believe that better memory is just a matter of training. A consequence of this false belief is the idea that impaired memory may be restored simply by practicing learning of word lists, pictures or other material. The implicit assumption underlying this reasoning is that memory is a unitary function which is responsible for success in all tasks having a memory component, and that this function responds like a "mental muscle" that can be strengthened with practice. However, repetitive practice of meaningless material (e.g., the repeated drill of word lists or other material) has very little or no generalization to everyday life or to untrained material (Glisky, 1997; Tate, 1997). This is not astonishing given that many different processes are involved in such diverse tasks as the learning of face-name associations, route-finding, remembering to go to the dinner party next Thursday, or what one was looking for in the living-room.

A good way to avoid conceptual failures when trying to develop memory rehabilitation programs is to base the program on a theoretical model about how memory works rather than on implicit assumptions. A scientific theory provides a framework for describing better the level of impairment (e.g., that amnesic patients have difficulty with "deep" encoding of information), gives clues about possible approaches to increase performance (e.g., encourage "deep" processing), and helps to evaluate such approaches (e.g., by controlling whether the benefice is due to the intervention or other factors, see Baddeley, 1992).

\section{COGNITIVE THEORY AND MEMORY REHABILITATION}

The understanding of memory impairment and the development of specific rehabilitation techniques rely on a conceptual framework that is the result of experimental studies with healthy participants and memory-impaired patients. The basic theoretical position is that memory is composed of several functionally distinct, and largely independent systems (Tulving, 1972, 1995; Squire et al., 1993; Gabrieli, 1998). Studies of impaired and preserved memory function in patients with amnesia have strongly contributed to the distinction between declarative and non-declarative memory systems. Declarative memory refers to memories that are accessible to conscious recollection and can be communicated to others, such as facts, events, or autobiographical knowledge in contrast to nondeclarative forms of memory such as skills, habits, and conditioned responses (Squire, 1987).

Numerous studies have demonstrated intact or relatively preserved abilities of amnesic patients in procedural learning (Corkin, 1968; Brooks and Baddeley, 1976; Cohen and Squire, 1980), priming (Warrington and Weiskrantz, 1968; Cermak et al., 1985; Shimamura, 1986), semantic memory (Kitchener et al., 1998; Van der Linden et al., 2001), or classical conditioning (Weiskrantz and Warrington, 1979; Daum et al., 1989; Woodruff-Pak, 1993). Since memory rehabilitation attempts to exploit preserved abilities these findings are of particular importance for the remediation of memory disorders. For example, patients who start to check their notebook for appointments following intensive repeated training 
may do so because they acquired a new habit. Conversely, implicit memory may impair performance when the source of the information is forgotten and the learner does not explicitly remember that the response was an error (Jacoby et al., 1989; Squire and McKee, 1993), which is particularly relevant in view of the use of errorless learning (a learning technique using conditions that attempt to limit the production of errors) in memory rehabilitation.

Another important line of research has attempted to identify the cognitive processes that are involved in the formation of memory traces. One of the first approaches, the levels-of-processing framework (Craik and Lockhart, 1972), predicts that different encoding manipulations result in successful or less successful recall of information. For example, recall of words is much better when participants perform a semantic judgment during learning compared to a phonological or perceptual judgment. More recent research has shown that recall is optimal when the processes evoked at recall match the processes that were involved at encoding (Graf and Ryan, 1990). Thus, when subjects make a phonological judgment about a word, they will later be better at recalling phonology than recalling the meaning of the word. One of the most powerful encoding manipulations that affect recall performance is mental imagery, which is frequently used to enhance learning (e.g., in face-name association learning) in memory-impaired patients. The beneficial effect of imagery has been attributed to the fact that concrete information (images) is encoded verbally and visually, while more abstract information (words) is only encoded verbally (Paivio, 1971). Interestingly, Paivio (1971) notes that the dual coding theory has its roots in the use of imagery as a memory aid by the ancient Greeks.

Another theoretical development that has influenced memory rehabilitation concerns operant conditioning or more generally skill learning. In contrast to research on mechanisms involved in the encoding and retrieval of factual information, the classical studies of operant learning have focused on the modification of behavior through reinforcement while deliberately ignoring cognitive processes (Schwartz and Reisberg, 1991). Though the basic principles of operant learning have been identified in animal research, similar rules determine performance of amnesic patients in some complex learning tasks (Oscar-Berman et al., 1976; Ptak et al., 2001b). A thorough analysis of operant mechanisms may help to decrease the frequency of problematic behavior often accompanying dense amnesia. For example, patiently answering repeated questions of an amnesic may reinforce the tendency of the patient to ask questions and thus increase their frequency.

Experimental research with memory-impaired participants has itself made a strong contribution to memory theory and memory rehabilitation. Several hypotheses were explored to explain the disturbance of episodic memory in amnesia, and each of them has suggested how memory could be enhanced. Thus, the hypothesis that amnesic patients encode information shallowly has lead to the idea that in order to improve acquisition "deep" (e.g., semantic) encoding should be encouraged (Cermak et al., 1973, 1974; Hirst and Wolpe, 1984). An alternative hypothesis posits that amnesic patients suffer from increased interference between previously learned and new information (Warrington and Weiskrantz, 1974, 1978; Van der Linden et al., 1993). Such findings suggest that in order to enhance learning in memory-impaired patients, interference should be limited as much as possible. In the same vein, recent studies showed that at least some of the severe forgetting observed in amnesics is the consequence of a disruption of memory consolidation by immediate post-learning interference (Dewar et al., 2009). A further proposal is that memory-impaired patients fail to encode the spatio-temporal context in which information was learned (Huppert and Piercy, 1976; Kopelman et al., 1997). As a consequence, patients acquire new information better when encoding of the learning context is facilitated. Finally, studies comparing amnesic patients with damage to different brain structures have revealed significant differences in behavior and performance in various experimental tasks. Thus, amnesia following damage to the medial temporal lobes is characterized by greater impairment of recognition memory than amnesia following diencephalic and prefrontal damage (Zangwill, 1966; Squire, 1981; Parkin, 1984). Conversely, damage to the basal forebrain and orbitofrontal cortex as well as acute diencephalic dysfunction are often characterized by unawareness of impairment, disorientation and spontaneous confabulations (Kopelman, 1995; Schnider and Ptak, 1999; Ptak et al., 2001a; Schnider, 2008; Nahum et al., 2009). These different types of amnesia present with clinically very distinct behavior and may therefore respond differently to specific interventions.

\section{HOW TO PLAN AN INTERVENTION}

Detailed planning of the intervention is essential for the success of any therapy. In the field of memory rehabilitation, a thorough therapy plan should provide measures of the quality and degree of impairment, identify target problems, anticipate a lack of compliance, and propose how to maintain acquired information.

\section{ASSESSING MEMORY DEFICITS}

The pattern of deficits displayed by a patient in memory tests is crucial for the choice of an intervention. For example, a patient with memory problems associated with slight language impairment might benefit less from a vanishing cues technique (a technique whereby prompts are provided whose number gradually decreases until prompting is no longer necessary) than a patient without such a deficit. Further, memory tests provide a common baseline on which different patients may be compared. However, complaints of memory-impaired patients and their relatives often concern the failure to retain material-specific knowledge (e.g., names or routes) and prospective memory (e.g., retention of appointments and scheduled tasks, Sohlberg et al., 1992b), which are often not assessed by memory tests. Therefore results of memory assessment do not necessarily reflect the degree of independence in activities of daily living (ADL), and we need to complement standardized tests with other forms of assessment techniques, such as direct observation, diaries or checklists, and behavioral assessment of everyday memory activities.

Classifying memory impairment according to the severity is presently the best predictor of success of techniques such as imagery mnemonics or errorless learning. Table 1 presents a tentative classification of the severity of memory problems based on learning capacity, spatio-temporal orientation, metamemory, and awareness of the deficit, as well as independence in ADL. 
Table 1 | Learning capacity, spatio-temporal orientation, awareness of the deficit, and independence in activities of daily living (ADL) as a function of the degree of memory impairment.

\begin{tabular}{|c|c|c|c|c|}
\hline $\begin{array}{l}\text { Degree of memory } \\
\text { impairment }\end{array}$ & Learning capacity & Orientation & $\begin{array}{l}\text { Awareness of } \\
\text { impairment }\end{array}$ & Independence in ADL \\
\hline I. Slight & $\begin{array}{l}\text { May acquire and retain repeatedly } \\
\text { presented information; recall is nearly } \\
\text { normal when cues are provided; normal } \\
\text { recognition }\end{array}$ & Normal & $\begin{array}{l}\text { Good knowledge of own } \\
\text { impairment; spontaneous } \\
\text { application of strategies to } \\
\text { improve performance }\end{array}$ & $\begin{array}{l}\text { Complete for ADL; able to exercise } \\
\text { professional activities when } \\
\text { working place is adapted }\end{array}$ \\
\hline II. Moderate & $\begin{array}{l}\text { Partial acquisition of new information; } \\
\text { strong interference effects; cueing helps, } \\
\text { but does not normalize performance; } \\
\text { recognition slightly impaired }\end{array}$ & $\begin{array}{l}\text { Unstable for } \\
\text { time and date }\end{array}$ & $\begin{array}{l}\text { Frequent complaints; } \\
\text { attempts to compensate } \\
\text { for memory failures }\end{array}$ & $\begin{array}{l}\text { Independence for routine tasks; } \\
\text { impaired acquisition of new } \\
\text { procedures; needs help with } \\
\text { administrative tasks }\end{array}$ \\
\hline III. Severe & $\begin{array}{l}\text { Extremely limited; cueing has slight } \\
\text { effects; recognition strongly impaired }\end{array}$ & $\begin{array}{l}\text { Temporal } \\
\text { disorientation } \\
\text { (time, date) }\end{array}$ & $\begin{array}{l}\text { Forgets being forgetful; } \\
\text { ineffective coping } \\
\text { strategies }\end{array}$ & $\begin{array}{l}\text { Routine tasks must be called to } \\
\text { mind; needs supervised training for } \\
\text { the acquisition of new procedures }\end{array}$ \\
\hline
\end{tabular}

\section{IDENTIFYING TARGET PROBLEMS}

Problem identification may prove difficult on the basis of a clinical interview with the patient because many patients with severe and very severe memory problems may "forget how forgetful they are" (Wilson and Moffat, 1992,p. 129) or tend to describe their failures in general terms (e.g., "I tend to forget everything"). The definition of target problems should therefore be based on information given by family members and behavioral observation. A functional analysis of forgetting also provides valuable information about possible reinforcement of target problems (Moffat, 1992). Such an analysis tries to identify whether the occurrence or frequency of specific target behaviors (e.g., asks her husband instead of consulting the notebook) depends on specific variables (e.g., the husband does answer instead of prompting the patient to consult the notebook). The control and suppression of undesirable reinforcement contingencies may prove to be the most difficult part of memory rehabilitation.

Memory rehabilitation should be centered on concrete goals (Wilson, 2009). When defining behavioral goals for the intervention it is important to be as specific and concrete as possible (e.g., "Will remember to take his medication in the evening"). It is of little help to define the problem in vague and general terms. In the case of inappropriate or socially unacceptable behavior it is important to describe in detail the circumstances in which the behavior was observed (e.g., Who was present? What happened immediately before? What were the consequences of the behavior?), and to note the frequency of its occurrence. Finally, the analysis of target problems may sometimes reveal that the observed "memory" problems are in fact consequences of impaired time estimation or action sequencing and therefore reflect executive rather than memory problems (Ptak and Schnider, 2004).

\section{ENHANCING LEARNING IN MEMORY-IMPAIRED PATIENTS}

Wilson (1992) states several rules how to organize information in order to increase the chance that patients retain it. Information should be given in very simple, concrete form; the amount of information given at once should be minimal; the same information should be presented repeatedly; patients should be encouraged to restate in their own words what they have learned; finally, patients should be encouraged to build associations between similar information. Repeated presentation is necessary when clinicians attempt to teach specific information such as new facts or skills to amnesic patients (Glisky and Schacter, 1989; Andrewes and Gielewski, 1999; Brooks et al., 1999). In this respect, a recent study conducted in a patient with limbic encephalitis showed that memory of events that happened during the day can be improved when pictures generated automatically at regular intervals by a portable camera ("SenseCam") are subsequently viewed in the form of a movie (Berry et al., 2007).

In patients with impaired attention encoding may be enhanced through self-cueing. The experimenter provides external signals (e.g., "BE ATTENTIVE," while producing a loud noise) with the aim to increase alertness when important information is given. The patient is then encouraged to do the like whenever he/she encounters important information. The alerting signal is progressively diminished (e.g., patients are instructed only to say "I AM ATTENTIVE") and finally internalized (patients are instructed merely to think of the alerting signal). Self-cueing has been shown to increase alertness of patients with severe attentional disturbances (Robertson et al., 1992), though similar ideas have been used in the rehabilitation of prospective memory (Sohlberg and Mateer, 1989a).

\section{METHODS OF MEMORY REHABILITATION}

Three main types of memory rehabilitation strategies have been proposed: mnemonics aimed to optimize encoding and retrieval, teaching amnesic patients new factual or procedural knowledge by using techniques considered to exploit spared memory abilities, and compensating for memory deficits with memory aids. The choice of a particular technique depends essentially on the nature of the memory problem that has to be treated, the degree of impairment, the remaining memory abilities, and what memory strategies patients used before their illness. 


\section{OPTIMIZING ENCODING AND RETRIEVAL: MNEMONICS}

The most frequently used and best-evaluated techniques in memory rehabilitation can be classified as "internal" (verbal or imagery) mnemonics used to optimize encoding and retrieval (Van der Linden and Van der Kaa, 1989; Wilson, 2009). These include making up a story to connect words one has to retain, building an acronym, or rhyme mnemonics (Harris, 1992). Also, trying to find the first letter is a simple cuing aid facilitating the recall of specific information (usually names). However, the disadvantage of such mnemonic techniques is that they can only be used for specific material (e.g., shopping lists) and in very specific situations (e.g., when no written reminders are available). Consequently, even students do not often employ such mnemonics spontaneously. Nonetheless, a few studies have suggested that some mnemonic techniques (e.g., building associations and structuring the material) may result in better memory for new material (Doornheim and De Haan, 1998). For example, for slightly impaired patients who have a specific need to better retain texts, the PQRST technique will prove useful, because it has specifically been developed to enhance encoding of organized and meaningful material (Moffat, 1992). PQRST is an acronym of Preview (establish the general order of the text), Question (formulate main questions), Read (read carefully, thinking at the questions), State (summarize the main information), and Test (test your knowledge and whether you are able to answer the questions).

The mnemonic method whose efficacy has best been examined is mental imagery. Leng and Parkin (1988) reported that amnesic patients benefited from mental imagery when learning simple word associations. In a randomized study, Kaschel et al. (2002) compared a patient group with mild memory impairment receiving imagery-based training with a control group involved in pragmatic memory training. The program of the imagery group consisted of a skill-acquisition stage, in which patients trained to use mental imagery in increasingly demanding situations (e.g., imaging of single objects, multiple objects, and actions while the retrieval interval was gradually increased), and a transfer stage, in which patients exercised the use of mental imagery according to their individual needs (e.g., books relevant to the patient's job). The "pragmatic" group was taught how to use calendars and notebooks, or received attention and planning training. From all patients a prebaseline, a post-baseline, a post-training, and 3-month follow-up measure in several tests was obtained. The authors found specific improvements of the imagery group in immediate and delayed story recall and in delayed recall of appointments. In addition, following the intervention their memory was rated significantly better by relatives. These findings are noteworthy, as they suggest that the intensive training of an internal mnemonic strategy may lead to generalized application of this strategy to new material and have a differential impact on different aspects of memory functioning (Cicerone et al., 2005; das Nair and Lincoln, 2007). However, in the study by Kaschel et al. (2002) only mildly impaired and highly motivated patients were included (most of them willing to return to work). While mental imagery might be suited for such patients, it has been used with much less success with severely impaired patients. Thus, Wilson (1987) reported that self-generated images improved recall of patients with mild, but not of patients with severe memory problems. She found improved retention in both groups when patients were exposed to experimenter-drawn images during learning. In agreement with this finding presentation in pictorial form enhanced verbal recall even in severely confused and disoriented patients with post-traumatic amnesia, though the patients did not remember the learning session or the experimenter's face (Ptak et al., 1998). Imagery mnemonics also proved useful for learning face-name associations (Thoene and Glisky, 1995).

In sum, these studies show that mnemonics may significantly enhance memory of patients with mild to moderate memory impairment (Gade, 1994; Cicerone et al., 2005). Patients with mild memory impairment may use a mnemonic such as imagery spontaneously after intensive training. When using mnemonics, we need to take in account individual preferences and styles and to focus on material that will be useful in everyday life. It is also necessary to facilitate the transfer from the training program to real-life situations (Wilson, 2009).

\section{ACQUISITION OF NEW INFORMATION IN AMNESIA}

Rehabilitation of patients with severe and very severe memory impairment is extremely challenging. Nevertheless, the various studies that have documented preserved procedural, perceptual or semantic memory abilities in amnesia suggest that it is possible to exploit intact learning capabilities of amnesic patients in order to increase their autonomy in everyday life. Several techniques have been developed that may enhance new learning, or at least modify behavior of patients with amnesia.

The spaced-retrieval technique prompts recall of information over increasingly longer retention intervals. It is based on the observation that massed practice is a less efficient learning strategy than distributed practice (Ebbinghaus, 1885/1992; Landauer and Bjork, 1978). Spaced retrieval facilitates acquisition of new information irrespective of its modality and is therefore not reserved for memory therapy alone. Moffat (1992) therefore suggested that spaced retrieval might be used in the rehabilitation of various cognitive problems, such as dysgraphia or anomia. Schacter et al. (1985) were the first to show that the principle of spaced retrieval could be used in amnesic patients. Subsequently the method has been adapted for the rehabilitation of memory problems in Alzheimer's disease (Camp and Foss, 1997; Van der Linden et al., 2003). Sohlberg and Mateer (1989a) developed a prospective memory training method based on spaced retrieval, whose aim it was to enhance recall of scheduled tasks and appointments in memory-impaired patients. During training patients were asked to execute simple tasks in a specified number of minutes, beginning with tasks presented within a session and gradually expanding to longer intervals. The authors reported a progressive increase of the prospective memory span in three patients with severe brain injury (Sohlberg et al., 1992a,b). Patients with memory problems are often surprised when they give correct answers without remembering having been presented with the information in the past (Schacter et al., 1985). As this technique seems to occur without cognitive effort the efficacy of spaced retrieval has been attributed to implicit memory processes (Camp and Foss, 1997).

The vanishing cues method (Glisky et al., 1986b) involves giving subjects a cue (for example the first three letters of a word); across learning trials, cues are gradually withdrawn until responses are eventually given in the absence of cues. It has partly been 
motivated by the finding that amnesic patients exhibit a severe deficit in explicit memory tasks, but may show entirely intact performance when memory is assessed using implicit (e.g., word completion) tasks (Warrington and Weiskrantz, 1968; Cohen and Squire, 1980; Schacter, 1987). In their initial studies, Glisky et al. (1986a,b) examined whether amnesic patients were able to acquire the meaning of computer-related terms. In the acquisition phase, patients were shown incomplete sentences (e.g., "A sequence of characters enclosed in quotation marks is called a___") and were asked to type the target word ("STRING") that completed the sentence. If the patient did not know what to type he was shown the first letter. If necessary, additional letters of the target word were presented until the patient identified the correct word. The important finding of these studies is that though learning was laborious and required many more trials than in healthy participants, several amnesic patients were eventually able to acquire new semantic knowledge and to retain this knowledge over intervals of several months (Glisky and Schacter, 1988). Further, one amnesic patient (Glisky and Schacter, 1989) was trained to use a relatively complex data-entry procedure requiring the acquisition of 250 pieces of new information. Considering that the patients participating in these studies had dense amnesia these are very encouraging findings. However, more recent findings were less optimistic about the vanishing cues technique. Thus, Hunkin and Parkin (1995) did not find an advantage of the vanishing cues method over the classical anticipation learning method in memory-impaired patients.

Baddeley and Wilson (1994) criticized the vanishing cues procedure initially developed by Glisky et al. (1986a,b) by suggesting that it promotes the production of errors. This is the case especially in the initial learning trial where patients are required to guess a target word in response to its definition. According to Baddeley and Wilson, a crucial role of explicit memory in learning is to remember and eliminate errors. If explicit memory is impaired (as is the case in amnesia) acquisition of new information may fail due to interference by previous errors stored in implicit memory. To test their hypothesis, Baddeley and Wilson (1994) asked healthy participants and memory-impaired patients to learn a list of words either in an "errorful" or in an "errorless" condition. In the errorful condition, for each target word (e.g., QUOTE) participants were given the following instruction: "I am thinking of a five-letter word beginning with QU. Can you guess what it might be?” The subjects were encouraged to guess the word in order to provoke at least one error. In the errorless condition, participants were given the target word and asked to retain it. Results showed that the errorful condition particularly disrupted learning of memory-impaired patients, while there was no difference between conditions for younger or older healthy participants. In addition, a detailed analysis of the experimental data showed that errorless learning was characterized both by faster acquisition and less forgetting of items. Thus, this technique limits the opportunity to commit errors by repeatedly exposing the patients with the correct response rather than asking them to guess or explicitly retrieve it.

These findings motivated several authors to further attempt to specify the strengths and limits of errorless learning. The findings generally support the superiority of errorless learning over a trialand-error condition when memory-impaired patients learn simple verbal associations (Hamann and Squire, 1995; Hunkin et al., 1998b;
Komatsu et al., 2000; Kalla et al., 2001) or more complex verbal (e.g., learning to use a simple computer program, Hunkin et al., 1998a; Ehlhardt et al., 2005) or procedural knowledge (Andrewes and Gielewski, 1999). Recently, Kessels and de Haan (2003) compared the effectiveness of the method of vanishing cues and errorless learning in a meta-analysis of current research. They found a significant effect-size of memory improvement with errorless learning, but a non-significant effect-size for vanishing cues. They attributed this finding to the fact that vanishing cues provoke errors in memory-impaired patients, leading to trial-and-error learning and thus increased interference. However, albeit encouraging these results should be considered with caution. First, in the control condition used in many studies, errors were explicitly provoked, leading to somewhat artificial learning. The effect-size of errorless learning might therefore have been inflated and its efficacy overestimated. Second, Evans et al. (2000) observed a benefit of errorless learning (in comparison to a trial-and-error condition) only when recall was cued with the first letter of the target word, but not in free recall. The authors concluded that "errorless learning methods will have their greatest advantage over trial-and-error methods in those situations where implicit learning is possible and where learning is tested in a manner that facilitates the retrieval of implicit information" (p. 95).

We found a similar result in SK, a patient with severe amnesia following traumatic brain injury who was asked to learn eight names of staff members shown on photographs. We combined errorless learning with a cueing method, whereby an increasing number of letters of each name was provided until the name was recalled. Figure 1A shows the percentage of names recalled across 15 learning sessions when the patient was given the first letter as cue as well as the number of correctly recalled names when no cues were provided. The figure shows that (slight) learning occurred essentially in the first eight sessions, after which performance leveled off. In the first five sessions the patient needed 254 letter cues to recall $100 \%$ of all names against 176 cues in the last five sessions. Despite this apparent progress he showed no change in his ability to recall the learned names when no cue was given, and there was no correlation between cued recall and free recall. In contrast, in a second patient (KA, who became amnesic following bleeding from the anterior communicating artery) the same procedure resulted in significantly better recall of names of hospital staff irrespective of whether performance was measured by giving the first letter of the name (cued recall) or by free recall (Figure 1B). In addition, this patient also showed benefits in delayed recall. Thus, while in SK learning enhanced acquisition only when the patient did not attempt to access explicit information a generalization to immediate and delayed recall was found in KA. Interestingly, though the neuropsychological examination showed severely impaired acquisition of verbal or non-verbal information in both patients, only KA was consistently disoriented in time and space, unaware of his cognitive deficits, and exhibited more severe executive impairment (action planning, sequencing, verbal production and reasoning) than SK.

Similar differences in errorless learning between individual patients were reported by Van der Linden et al. (1994), who observed that the flexibility of newly acquired semantic knowledge varied between amnesic patients with comparable degrees of memory 

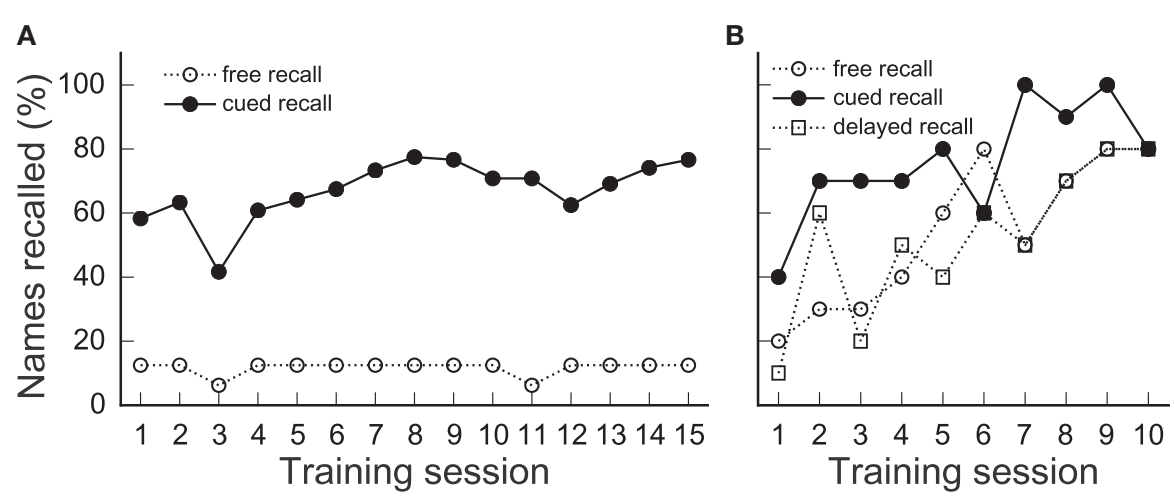

FIGURE 1 | Acquisition of names using errorless leaming. (A) Amnesic patient SK learned to recall eight names of hospital staff depicted on photographs. He needed progressively less letter cues to recall these names; nevertheless, free recall remained unchanged across 15 sessions. (B) KA successfully acquired 10 names across 10 learning sessions. His performance gradually increased whether cued recall (only first letter provided) or free recall (immediate or delayed) were tested. impairment: while recall of one patient depended on the presence of the first letter cue, the other patient eventually became independent of the cues and thus showed more flexible knowledge.

These findings suggest that in order to fully comprehend the advantages and working principles of errorless learning and vanishing cues one should attempt to identify the memory processes on which these techniques rely. Glisky and colleagues (Glisky et al., 1986a,b; Glisky and Schacter, 1988, 1989; Glisky, 1992) observed that recall of amnesic patients who had acquired new information using the method of vanishing cues was highly specific to the material used. These authors found that though able to acquire a computer-related vocabulary, amnesic patients could not access their new knowledge if they were probed differently than in the learning session, unless transfer of new knowledge was tested with a minor variation of the exercised task (Glisky, 1992). This hyperspecificity of new knowledge suggests that recall of newly acquired information was based on preserved implicit memory of amnesic patients. This hypothesis was tested by Hunkin et al. (1998b), who confirmed the superiority of errorless learning over errorful learning, but found no correlation between the responses of memory-impaired patients produced in the errorless condition and their performance in an implicit memory test. The authors concluded that the benefits of errorless learning were not explained by enhanced use of implicit memory, but rather resulted from error prevention in explicit memory. However, the results might have been influenced by the memory test that was employed to measure implicit memory. Indeed, a recent study by Riley et al. (2004) found evidence that the method of vanishing cues results in robust implicit memory (priming) if it is measured with a task requiring participants to complete word stems, but not if other types of priming are examined.

The advantage of errorless learning (elimination of interference by self-generated errors) and the method of vanishing cues (active and effortful learning) has motivated several authors to combine the two methods and thus to multiply their effectiveness (Evans et al., 2000; Pitel et al., 2006). Komatsu et al. (2000) explored the learning of face-name associations by Korsakoff patients using four study conditions that differed from one another with respect to error frequency and the effort required by the task. The results showed an advantage of errorless learning while the effort factor was found to have little effect. Tailby and Haslam (2003) compared the original errorless learning condition (Baddeley and Wilson, 1994) to errorless learning with self-generated answers. In the latter condition, patients were given sufficient information permitting them to generate the target word (e.g. "I'm thinking of a five-letter word beginning with BR, and this word describes a food made of flour, liquid and yeast which is baked and then sliced to make sandwiches"), thus combining the advantages of interference elimination with effortful learning. This modified method was superior than the approach originally chosen by Baddeley and Wilson (1994).

Thus, despite intense study, the working principles and efficacy of errorless and effortless learning remain a matter of debate (Clare and Jones, 2008). The reasons why the clinical relevance of some studies is difficult to judge is that they focused on experimental (e.g., learning of word lists) rather than functional tasks and measured outcome at short intervals (Sohlberg and Mateer, 2001). Nevertheless, the majority of studies including patients with severe memory impairment show that errorless learning significantly enhances learning of verbal material, such as the names of people. Evidence of learning is particularly strong when a close correspondence between the format of learned items and the format of test items is established. New knowledge acquired using these methods is often inflexible and recall is best when there is a strong correspondence between contextual cues at recall with cues that were present when information was encoded. The lack of flexibility and gradual increase of performance suggest that information acquisition is based on implicit learning of new associations rather than on explicit memory, which is reminiscent of the findings reported by experimental studies that examined complex contingency learning in amnesic patients. While in some paradigms amnesics show intact acquisition of associations between a behavioral choice and an outcome (Knowlton et al., 1994; Ptak et al., 2001b), this is not the case when the current choice is based on a conscious record of previous outcomes (Gutbrod et al., 2006). Interestingly, with extensive training severely amnesic patients are capable of acquiring relatively flexible complex knowledge (such as is required for text processing on a microcomputer, Van der 
Linden and Coyette, 1995; Todd and Barrow, 2008), suggesting that some generalization of learning may be obtained with overlearning (Butters et al., 1993). Taken together, these findings suggest that even subtle differences between tasks are important predictors of the capacity of amnesic patients to exhibit intact learning. A careful analysis of the task demands is therefore critical for the success of a therapeutic intervention.

Finally, it seems pragmatic to adopt a strategy that attempts to reduce errors also in the rehabilitation of patients with paramnestic disturbances such as reduplicative paramnesia or spontaneous confabulations. Patients with spontaneous confabulations formulate ideas and plan actions that are incompatible with the current spatio-temporal context (Schnider, 2003). They may insist on the veracity of their false beliefs and argue with hospital staff who try to correct them (Ptak and Schnider, 1999). Though the confabulatory state often resolves within several weeks or months (Schnider et al., 2000), managing behavior of patients who are convinced to have an appointment or a task to do is a challenge for the entire rehabilitation staff. In agreement with the principles of errorless learning the most sensible strategy is to limit the production of confabulations and thus to prevent situations in which false beliefs have to be corrected.

\section{COPING WITH MEMORY PROBLEMS: EXTERNAL MEMORY AIDS AND MANAGEMENT OF BEHAVIOR}

The primary objective of memory therapy is to render patients as independent as possible in activities of daily life. Ecological rehabilitation does therefore not only target the acquisition of specific knowledge (e.g., names of people), but also prospective memory, that is the ability to remember to do something in the future (Fish et al., 2009). Systematic training of the use of external memory aids is the most frequent and potentially the most beneficial strategy to compensate for prospective memory failures (Fluharty and Priddy, 1993). However, to learn how to use an external aid may prove difficult for memory-impaired patients because using such an aid is in itself a memory task (Sohlberg and Mateer, 2001). Patients who forget what they have forgotten in the past often fail to anticipate what they might forget in the future. Without support by therapists some patients might eventually develop more or less sophisticated notebook systems (Wilson et al., 1997b), but this is often an exception rather than the rule. Evans et al. (2003) showed that the variables that best predict the use of memory aids (such as calendars, wall charts, and notebooks) in people with acquired brain injury were: current age (the younger the person, the more likely she uses memory aids), time since injury (the longer the time since injury the less memory aids are used) and the number of aids used prior to injury.

In order to facilitate the use of a memory notebook, several authors have developed formal training procedures (Sohlberg and Mateer, 1989b; Burke et al., 1994; Van der Linden and Coyette, 1995; Donaghy and Williams, 1996; Squires et al., 1997). Thus, Sohlberg and Mateer (1989b) divide the notebook into several sections which reflect the individual needs of the patient (e.g., things to do, names of people to remember, maps etc.) and train its use in three phases. In the acquisition phase patients become familiar with the different sections and their contents through repetitive questions (e.g., "Name the five sections of your notebook," "Where should you record information about appointments?"). In the application phase, the appropriate use of the notebook is exercised in role-play situations. In the final adaptation phase, training is performed in naturalistic situations. Sohlberg and Mateer (1989a) trained several global amnesic patients with this method, and observed that the patients continued to use compensatory systems after training was stopped. It must be noted, however, that these patients exercised the use of a notebook for 6-8 months in daily sessions. Similar methods were proposed by Donaghy and Williams (1996) and by Squires et al. (1996), who observed a reduction of repeated questions in an amnesic patient after notebook training.

Some authors recommend the use of electronic organizers (Kapur et al., 2004). The advantage of electronic systems compared to notebooks is that one or several alarm events may be set that provide an external cue triggering a predefined action. Among the disadvantages are the costs, complexity, and the fact that many commercially available organizers show small text and have very small buttons, which makes them unsuitable for patients with diminished sensory functions (however, note that several systems have been developed for specific rehabilitation purpose, LoPresti et al., 2004). For patients who are familiar with a mobile phone one might therefore prefer to trigger prospective memory tasks with SMS messages, rather than newly introducing an organizer (Fish et al., 2007; Culley and Evans, 2010).

An increasing number of studies evaluate the potential benefit of external cuing devices for memory-impaired patients. Pitel et al. (2006) reported that following traumatic brain injury two patients were able to acquire limited procedural knowledge about how to use an electronic cuing device (e.g., programming appointments); however, none of them used the device in everyday life. Wilson et al. (1997a, 2001) examined the effects of a reminder system termed Neuropage $e^{\varpi}$ on prospective memory in a large group of patients with different etiologies and different degrees of prospective memory impairment. Neuropage ${ }^{\varpi}$ is a communication system which enables one to send simple alphanumeric messages to a pager carried by the patient. The treatment program targeted individual prospective memory failures; therefore, the messages mostly contained information recalling a specific task that had to be done at a specific time. In a pilot study with 15 memory-impaired patients Wilson et al. (1997a) found that the proportion of target tasks that were completed by the patients increased from 37 to $85 \%$ when the pager was introduced. In a single-case study, Evans et al. (1998) confirmed the beneficial effect of the pager system on execution of target tasks in a patient with a severe dysexecutive syndrome characterized by impaired attention to action, difficulty with action planning and ritual-like dysfunctional behaviors. After introduction of the pager, the patient showed a significant increase of the probability to carry out the target actions on time. More recently, Wilson et al. (2001) performed a randomized, crossover study on 143 memory-impaired patients with various etiologies. The participants were randomly assigned to group $A$, which received the pager for 7 weeks immediately post-baseline, or group B, receiving the pager once the treatment phase of group A had finished. The results confirmed the beneficial effect of the pager system, as the proportion of completed target tasks increased in both groups during the treatment phase, but not during baseline. In addition, the authors found that in some patients withdrawal of the pager 
did not reduce the number of target behaviors completed, while in others the proportion of completed target tasks fell to baseline level. Finally, Svoboda and Richards (2009) demonstrated the potential of a training program in enabling an individual with relatively severe memory impairments to autonomously support her memory functioning using a commercial smartphone. The patient demonstrated consistent and creative generalization of acquired smartphone skills to various everyday memory problems. In a recent study the same authors reported less forgetting of prospective memory tasks (phone calls, real-life events) following systematic training in the use of a smartphone in a young patient with severe memory problems (Svoboda et al., 2010). In addition, this patient showed increased confidence in dealing with memory demanding situations, and the intervention resulted in reduced caregiver strain as reported by her mother. Similarly, a significant reduction of caregiver strain has been observed following intervention using Neuropage $^{\circledast}$ (Teasdale et al., 2009). This finding is of particular relevance for the rehabilitation of memory-impaired patients, as care for these patients, many of whom have minor or no motor impairment and therefore live at home, is often a source of strain to family members.

Together, these findings show that - at least in some patients external cues are not merely a compensation of faulty memory, but trigger the development of habits for the target tasks and, in the best case, generalization to non-target tasks. An important additional effect is increased confidence in dealing with memory tasks, greater independence of the patient and reduced caregiver strain. The studies of external cueing systems emphasize the necessity to examine the effectiveness of different rehabilitation strategies as a function of the cognitive impairments and resources of individual patients.

\section{CONCLUSIONS}

This review of the current evidence regarding the failures and successes of memory rehabilitation shows that several promising approaches have been developed in the last 30 years. In the minds of professionals (though not necessarily in public opinion) memory therapy is no longer repetitive drill, but the application of theoretically founded techniques to enhance material-specific learning and effective compensation of memory failures. The methods of vanishing cues, spaced retrieval, and errorless learning demonstrate

\section{REFERENCES}

Andrewes, D., and Gielewski, E. (1999). The work rehabilitation of a herpes simplex encephalitis patient with anterograde amnesia. Neuropsychol. Rehabil. 9, 77-99.

Baddeley, A., and Wilson, B. A. (1994). When implicit learning fails: amnesia and the problem of error elimination. Neuropsychologia 32, 53-68.

Baddeley, A. D. (1992). "Memory theory and memory therapy," in Clinical Management of Memory Problems, eds B. A. Wilson and N. Moffat (London: Chapman \& Hall), 1-31.

Berry, E., Kapur, N., Williams, L., Hodges, S., Watson, P., Smyth, G., Srinisvanan, J., Smith, R., Wilson, B., and Wood, K.
(2007). The use of a wearable camera, SenseCam, as a pictorial diary to improve autobiographical memory in a patient with encephalitis : a preliminary report. Neuropsychol. Rehab. 17, 582-601.

Brooks, B. M., McNeil, J. E., Rose, F. D., Greenwood, R. J., Attree, E. A., and Leadbetter,A.G. (1999). Routelearning in a case of amnesia: a preliminary investigation into the efficacy of training in a virtual environment. Neuropsychol. Rehabil. 9, 63-76.

Brooks, D. N., and Baddeley, A. D. (1976). What can amnesic patients learn? Neuropsychologia 14, 111-122.

Burke, J. M., Danick, J. A., Bemis, B., and Durgin, C. J. (1994). A process

that even patients with dense amnesia are able to acquire new information. External cuing systems and memory notebooks show their benefits when memory-impaired patients must perform prospective memory tasks. The use of a memory notebook might be indicated to improve self-management of the patient, provided their use is repeatedly exercised with the patient following a structured acquisition program.

On the other hand, knowledge about the efficacy of rehabilitation techniques is still lacking. Only few randomized, controlled studies have been published that compare the efficacy of different treatment methods (Cicerone et al., 2000, 2005). A difficulty posed by the conduct of randomized controlled trials in the context of cognitive rehabilitation is the substantive heterogeneity of the patient population. Consequently, rigorous single-case designs can provide very useful information about the conduct and outcome of rehabilitative intervention (Mateer, 2009). In several studies, memory rehabilitation was merely the attempt to teach information with low ecological value to severely impaired patients. Also, acquisition of new information by patients with severe memory failures is slavish and its recall often depends on the external cues provided by the examiner. Thus, in addition to clarifying the working principles of rehabilitation techniques future studies should address the following questions. First, it is important to develop new or adapt existing methods that allow patients with severe memory impairment to learn how to acquire new information without external help. One possibility is to develop computer programs that permit self-administration of learning sessions using vanishing cues (however, note that the use of a microcomputer is in itself a task that has to be learned). Second, given the finding that some patients benefit from an intervention while others do less or not at all, it is important to clarify whether benefits from a particular intervention are predictable based on a qualitative pattern of deficits. Finally, the knowledge about the efficacy of different intervention methods as compared to others is still fragmentary and needs to be extended by future studies.

\section{ACKNOWLEDGMENT}

Support from the Swiss National Science Foundation (grant 320000-113438 to Radek Ptak and grant 320000-113436 to Armin Schnider).

approach to memory book training for neurological patients. Brain Inj. $8,71-81$.

Butters, M. A., Glisky, E. L., and Schacter, D. L. (1993). Transfer of new learning in memory-impaired patients. J. Clin. Exp. Neuropsychol. 15, 219-230.

Camp, C., and Foss, J. (1997). “Designing ecologically valid memory interventions for persons with dementia," in Intersections in Basic and Applied Memory Research, eds D. Payne, and Conrad, F. (Mahwah, NJ: Erlbaum), 311-325.

Cermak, L. S., Butters, N., and Gerrein, J. (1973). The extent of the verbal encoding ability of Korsakoff patients. Neuropsychologia 11, 85-94.
Cermak, L. S., Butters, N., and Moreines, J. (1974). Some analyses of the verbal encoding deficit of alcoholic Korsakoff patients. Brain Lang. 1, 141-150.

Cermak, L.S., Talbot, N., Chandler, K., and Wolbarst, L. R. (1985). The perceptual priming phenomenon in amnesia. Neuropsychologia 23, 615-622.

Cicerone, K. D., Dahlberg, C., Kalmar, K., Langenbahn, D. M., Malec, J. F., Bergquist, T. F., Felicetti, T., Giacino, J. T., Harley, J. P., Harrington, D. E., Herzog, J., Kneipp, S., Laatsch, L., and Morse, P. A. (2000). Evidence-based cognitive rehabilitation: recommendations for clinical practice. Arch. Phys. Med. Rehabil. 81, 1596-1615. 
Cicerone, K. D., Dahlberg, C., Malec, J. F., Langenbahn, D. M., Felicetti, T., Kneipp, S., Ellmo, W., Kalmar, K., Giacino, J. T., Harley, J. P., Laatsch, L., Morse, P. A., and Catanese, J. (2005). Evidence-based cognitive rehabilitation: updated review of the literature from 1998 through 2002. Arch. Phys. Med. Rehabil. 86, 1681-1692.

Clare, L., and Jones, R. S. P. (2008). Errorless learning in the rehabilitation of memory impairment: a critical review. Neuropsychol. Rev. 18, 1-23.

Cohen, N. J., and Squire, L. R. (1980). Preserved learning and retention of pattern-analysing skill in amnesia: dissociation of knowing how and knowing that. Science 210, 207-210.

Corkin, S. (1968). Acquisition of motor skill after bilateral medial temporallobe excision. Neuropsychologia 6, 255-265.

Craik, F. I. M., and Lockhart, R. S. (1972). Levels of processing: a framework for memory research. J. Verbal Learn. Verbal Behav. 11, 671-684.

Culley, C., and Evans, J. J. (2010). SMS text messaging as a means of increasing recall of therapy goals in brain injury rehabilitation: a single-blind withinsubjects trial. Neuropsychol. Rehabil. 20, 103-119.

das Nair, R., and Lincoln, N. (2007). Cognitive rehabilitation for memory deficits following stroke. Cochrane Database Syst. Rev. doi: 10.1002/14651858.CD002293.pub2.

Daum, I., Channon, S., and Canavar, A. (1989). Classical conditioning in patients with severe memory problems. J. Neurol. Neurosurg. Psychiatr. $52,47-51$.

Dewar, M., Fernandez Garcia, Y., Cowan, N., and Della Sala, S. (2009). Delaying interference enhances consolidation in amnesic patients. Neuropsychology $23,627-634$.

Donaghy, S., and Williams, W. (1996). A new protocol for training severely impaired patients in the usage of memory journals. Brain Inj. 12, 1061-1076.

Doornheim, K., and De Haan, E. H. F. (1998). Cognitive training for memory deficits in stroke patients. Neuropsychol. Rehabil. 8, 393-400.

Ebbinghaus, H. (1885/1992). Über das Gedächtnis. Untersuchungen zur experimentellen Psychologie. Darmstadt: Wissenschaftliche Buchgesellschaft.

Ehlhardt, L. A., Sohlberg, M. M., Glang, A., and Albin, R. (2005). TEACH-M: a pilot study evaluating an instructional sequence for persons with impaired memory and executive functions. Brain Inj. 19, 569-583.

Evans, J. J., Emslie, H., and Wilson, B. A. (1998). External cueing systems in the rehabilitation of executiveimpairments of action. J. Int. Neuropsychol. Soc. 4 399-408.

Evans, J. J., Wilson, B. A., Schuri, U., Andrade, J., Baddeley, A., Bruna, O., Canavan, T., Della Sala, S., Green, R., Laaksonen, R., Lorenzi, L., and Taussik, I. (2000). A comparison of "errorless" and "trial-and-error" learning methods for teaching individuals with acquired memory deficits. Neuropsychol. Rehabil. 10, 67-101.

Evans, J., Wilson, B., Needham, P., and Brentnall, S. (2003). Who makes good use of memory aids? Results of a survey of people with acquired brain injury. J. Int. Neuropsychol. Soc. 9, 922-935.

Fish, J., Evans, J. J., Nimmo, M., Martin, E., Kersel, D., Bateman, A., Wilson, B. A., and Manly, T. (2007). Rehabilitation of executive dysfunction following brain injury: "content-free" cueing improves everyday prospective memory performance. Neuropsychologia 45 , 1318-1330.

Fish, J., Mandly, T., and Wilson, B. A. (2009). "Rehabilitation for prospective memory problems resulting from acquired brain injury," in The Rehabilitation of Executive Disorders: A Guide to Theory and Practice, eds M. Oddy and A. Worthington (Oxford: Oxford University Press), 75-95.

Fluharty, G., and Priddy, D. (1993). Methods of increasing client acceptance of a memory book. Brain Inj. 7, 85-88.

Gabrieli, J.D. E. (1998). Cognitive neuroscience of human memory. Annu. Rev. Psychol. 49, 87-115.

Gade, A. (1994). "Imagery as a mnemonic aid in amnesia patients: effects of amnesia subtype and severity," in Cognitive Neuropsychology and Cognitive Rehabilitation, eds M. J. Riddoch and G. W. Humphreys (Hove: Lawrence Erlbaum Associates), 571-589.

Glisky, E. L. (1992). Acquisition and transfer of declarative and procedural knowledge by memory-impaired patients: a computer data-entry task. Neuropsychologia 30, 899-910.

Glisky, E. L. (1997). "Rehabilitation of memory dysfunction," in Behavioral Neurology and Neuropsychology, eds T. E. Feinberg and M. J. Farah (New York: McGraw-Hill), 491-495.

Glisky, E. L., and Schacter, D. L. (1988). Long-term retention of computer learning by patients with memory disorders. Neuropsychologia 26 , 173-178.

Glisky, E. L., and Schacter, D. L. (1989). Extending the limits of complex learning in organic amnesia: computer training in a vocational domain. Neuropsychologia 27, 107-120.
Glisky, E. L., Schacter, D. L., and Tulving, E. (1986a).Computer learning by memory impaired patients: acquisition and retention of complex knowledge. Neuropsychologia 24, 313-328.

Glisky, E. L., Schacter, D. L., and Tulving, E. (1986b). Learning and retention of computer-related vocabulary in amnesic patients: method of vanishing cues. J. Clin. Exp. Neuropsychol. 8, 292-312. Graf, P., and Ryan, L. (1990). Transferappropriate processing for implicit and explicit memory. J. Exp. Psychol. Learn. Mem. Cogn. 16, 978-992.

Gutbrod, K., Krouzel, C., Hofer, H., Müri, R., Perrig, W., and Ptak, R. (2006) Decision-making in amnesia: do advantageous decisions require conscious knowledge of previous behavioural choices? Neuropsychologia 44 1315-1324.

Hamann, S. B., and Squire, L. R. (1995). On the acquisition of new declarative knowledge in amnesia. Behav. Neurosci. 109, 1027-1044.

Harris, J. E. (1992). "Ways to help memory," in Clinical Management of Memory Problems, eds B. A. Wilson and N. Moffat (London: Chapman \& Hall), 59-85.

Hirst, W., and Wolpe, B. T. (1984) Encoding of spatial relations with amnesia. Neuropsychologia 22, 631-634.

Hunkin, N., and Parkin, A. (1995). The method of vanishing cues : an evaluation of its effectiveness in teaching memory-impaired individuals. Neuropsychologia 33, 1255-1279.

Hunkin, N. M., Squires, E. J., Aldrich, F. K., and Parkin, A. J. (1998a). Errorless learning and the acquisition of word processing skills. Neuropsychol. Rehabil. 8, 433-449.

Hunkin, N. M., Squires, E. J., Parkin, A. J., and Tidy, J.A. (1998b). Are the benefits of errorless learning dependent on implicit memory? Neuropsychologia 36, 25-36.

Huppert, F. A., and Piercy, M. (1976) Recognition memory in amnesic patients: effects of temporal context and familiarity of material. Cortex 12, 3-20.

Jacoby, L. L., Kelley, C. M., Brown, J., and Jasechko, J. (1989). Becoming famous overnight: limits on the ability to avoid unconscious influences of the past. $J$. Pers. Soc. Psychol. 56, 326-338.

Kalla, T., Downes, J. J., and van den Broek, M. (2001). The pre-exposure technique: enhancing the effects of errorless learning in the acquisition of face-name associations. Neuropsychol. Rehabil. 11,1-16.

Kapur, N., Glisky, E. L., and Wilson, B. A. (2004). Technological memory aids for people with memory deficits. Neuropsychol. Rehabil. 14, 41-60.
Kaschel, R., Della Sala, S., Cantagallo, A., Fahlböck, A., Laaksonen, R., and Kazen, M. (2002). Imagery mnemonics for the rehabilitation of memory: a randomised group controlled trial. Neuropsychol. Rehabil. 12, 127-153.

Kessels, R. P. C., and de Haan, E. H. F. (2003). Implicit learning in memory rehabilitation: a meta-analysis on errorless learning and vanishing cues methods. J. Clin. Exp. Neuropsychol. 25, 805-814.

Kitchener, E. G., Hodges, J. R., and McCarthy, R. (1998). Acquisition of post-morbid vocabulary and semantic facts in the absence of episodic memory. Brain 121, 1313-1327.

Knowlton, B. J., Squire, L. R., and Gluck, M. (1994). Probabilistic classification learning in amnesia. Learn. Mem. 1, 106-120.

Komatsu, S., Mimura, M., Kato, M. Wakamatsu, N., and Kashima, H. (2000). Errorless and effortful processes involved in the learning of face-name associations by patients with alcoholic Korsakoff's syndrome. Neuropsychol. Rehabil. 10, 113-132.

Kopelman, M. D. (1995). The Korsakoff syndrome. Br. J. Psychiatry 166, 154-173.

Kopelman, M. D., Stanhope, N., and Kingsley, D. (1997). Temporal and spatial context memory in patients with focal frontal, temporal lobe, and diencephalic lesions. Neuropsychologia 35, 1533-1545.

Landauer, T., and Bjork, R. (1978). "Optimal rehearsal patterns and name learning," in Practical Aspects of Memory, eds M. M. Gruneberg, P. E. Morris, and R. N. Sykes, (London: Academic Press), 625-632.

Leng, N. R. C., and Parkin, A. J. (1988). Amnesic patients can benefit from instructions to use imagery: evidence against the cognitive mediation hypothesis. Cortex 24, 33-39.

LoPresti, E. F., Mihailidis, A., and Kirsch, N. (2004). Assistive technology for cognitive rehabilitation: state of the art. Neuropsychol. Rehabil. 14, 5-39.

Mateer, C. (2009). Neuropsychological intervention for memory impairment and the role of single-case design methodologies. J. Int. Neuropsychol. Soc. 15, 623-628.

Moffat, N. (1992). "Strategies of memory therapy," in Clinical Management of Memory Problems, eds B. A. Wilson and N. Moffat (London: Chapman \& Hall), 86-119.

Nahum, L., Ptak, R., Leemann, B., and Schnider, A. (2009). Disorientation, confabulation, and extinction capacity: clues on how the brain creates reality. Biol. Psychiatry 65, 966-972.

Oscar-Berman, M., Sahakian, B. J., and Wikmark, G. (1976). Spatial 
probability learning by alcoholic Korsakoff patients. Q. J. Exp. Psychol. 2, 215-222.

Paivio, A. (1971). Imagery and Verbal Processes. New York: Holt, Rinehart, and Winston.

Parkin, A. J. (1984). Amnesic syndrome: a lesion-specific disorder? Cortex 20, 479-508.

Pitel, A. L., Beaunieux, H., Lebaron, N., Joyeux, F., Desgranges, B., and Eustache, F. (2006). Two case studies in the application of errorless learning techniques in memory impaired patients with additional executive deficits. Brain Inj. 20, 1099-1110.

Ptak, R., Birtoli, B., Imboden, H., Hauser, C., Weis, J., and Schnider, A. (2001a). Hypothalamic amnesia with confabulations. A clinico-pathological study. Neurology 56, 1597-1600.

Ptak, R., Gutbrod, K., Perrig, W., and Schnider, A. (2001b). Probabilistic learning with limbic or prefrontal damage. Behav. Neurosci. 115, 993-1001.

Ptak, R., Gutbrod, K., and Schnider, A. (1998). Association learning in the acute confusional state. J. Neurol. Neurosurg. Psychiatr. 65, 390-392.

Ptak, R., and Schnider, A. (1999). Spontaneous confabulations after orbitofrontal damage: the role of self-monitoring and temporal context confusion. Neurocase 5, 243-250.

Ptak, R., and Schnider, A. (2004). Disorganised memory after right dorsolateral prefrontal damage. Neurocase $10,52-59$.

Riley, G. A., Sotiriou, D., and Jaspal, S. (2004). Which is more effective in promoting implicit and explicit memory: the method of vanishing cues or errorless learning without fading? Neuropsychol. Rehabil. 14, 257-283.

Robertson, I. H., North, N., and Geggie, C. (1992). Spatio-motor cueing in unilateral neglect: three single case studies of its therapeutic effects. J. Neurol. Neurosurg. Psychiatr. 55, 799-805.

Schacter, D. L. (1987). Implicit memory: history and current status. J. Exp. Psychol. Learn. Mem. Cogn. 13, 501-518.

Schacter, D. L., Rich, S. A., and Stampp, M.S. (1985). Remediation of memory disorders: experimental evaluation of the spaced retrieval technique. J. Clin. Exp. Neuropsychol. 7, 79-96.

Schnider, A. (2003). Spontaneous confabulation and the adaptation of thought to ongoing reality. Nat. Rev. Neurosci. 4, 662-671.

Schnider, A. (2008). The Confabulating Mind. How the Brain Creates Reality. Oxford: Oxford University Press.

Schnider, A., and Ptak, R. (1999). Spontaneous confabulators fail to suppress currently irrelevant memory traces. Nat. Neurosci. 2, 677-681.

Schnider, A., Ptak, R., von Däniken, C. and Remonda, L. (2000). Recovery from spontaneous confabulations parallels recovery of temporal confusion in memory. Neurology 55, 74-83.

Schwartz, B., and Reisberg, D. (1991). Learning and Memory. New York: Norton and Company.

Shimamura, A. P. (1986). Priming effects in amnesia: Evidence for a dissociable memory function. Q. J. Exp. Psychol. 38A, 619-644.

Sohlberg, M. M., and Mateer, C. A. (1989a). Introduction to Cognitive Rehabilitation. New York: Guilford Press.

Sohlberg, M. M., and Mateer, C. A. (1989b). Training use of compensatory memory books: a three stage behavioral approach. J. Clin. Exp. Neuropsychol. 11, 871-891.

Sohlberg, M.M., and Mateer, C.A. (2001) Cognitive Rehabilitation. An Integrative Neuropsychological Approach. New York: Guilford Press.

Sohlberg, M.M., White, O., Evans, E., and Mateer, C. (1992a). Background and initial case studies into the effects of prospective memory training. Brain Inj. 6, 129-138.

Sohlberg, M. M., White, O., Evans, E., and Mateer, C. (1992b). An investigation of the effects of prospective memory training. Brain Inj. 6, 139-154.

Squire, L. R. (1981). Two forms of human amnesia: an analysis of forgetting. J. Neurosci. 1, 635-640

Squire, L. R. (1987). Memory and Brain. New York: Oxford University Press.

Squire, L. R., Knowlton, B., and Musen, G. (1993). The structure and organization of memory. Annu. Rev. Psychol. $44,453-495$.

Squire, L. R., and McKee, R. D. (1993). Declarative and nondeclarative memory in opposition: when prior events influence amnesic patients more than normal subjects. Mem. Cogn. $21,424-430$.

Squires, E. J., Hunkin, N. M., and Parkin A. J. (1996). Memory notebook training in a case of severe amnesia: generalising from paired associate learning to real life. Neuropsychol. Rehabil. 6, 55-65.

Squires, E. J., Hunkin, N. M., and Parkin, A. J. (1997). "Take note: using errorless learning to promote memory notebook training," in Case Studies in the Neuropsychology of Memory, ed. A. J. Parkin (Hove: Psychology Press), 191-203.

Svoboda, E., and Richards, B. (2009) Compensating for anterograde amnesia: a new training method that capitalizes on emerging smartphone technologies. J. Int. Neuropsychol. Soc. $15,629-638$.

Svoboda, E., Richards, B., Polsinelli, A., and Guger, S. (2010). A theorydriven training programme in the use of emerging commercial technology: application to an adolescent with severe memory impairment. Neuropsychol. Rehabil. 1-25. doi: 10.1080/09602011003669918. (In press).

Tailby, R., and Haslam, C. (2003). An investigation of errorless learning in memory-impaired patients: improving the technique and clarifying theory. Neuropsychologia 41, 1230-1240

Tate, R. L. (1997). Beyond one-bun, two-shoe: recent advances in the psychological rehabilitation of memory disorders after acquired brain injury. Brain Inj. 11, 907-918.

Teasdale, T. W., Emslie, H., Quirk, K. Evans, J., Fish, J., and Wilson, B. A (2009). Alleviation of carer strain during the use of the NeuroPage device by people with acquired brain injury. J. Neurol. Neurosurg. Psychiatr. $80,781-783$

Thoene,A., and Glisky, E. (1995). Learning of name-face associations in memoryimpaired patients : a comparison of different training procedures. J. Int Neuropsychol. soc. 1, 29-38.

Todd, M., and Barrow, C. (2008). Teaching memory-impaired people to touch type: the acquisition of a useful complex perceptual-motor skill. Neuropsychol. Rehabil. 18, 486-506.

Tulving, E. (1972)."Episodic and semantic memory," in Organisation of Memory, eds E. Tulving and W. Donaldson (New York: Academic Press), 381-403.

Tulving, E. (1995). "Organization of memory: quo vadis?" in The Cognitive Neurosciences, ed. M. S. Gazzaniga (Cambridge, MA: MIT Press), 839-847.

Van der Linden, M., Bruyer, R., Roland, J., and Schils, J. P. (1993). Proactive interference in patients with amnesia due to anterior communicating artery aneurysm rupture. J. Clin. Exp. Neuropsychol. 15, 525-536.

Van der Linden, M., Cornil, V., Meulemans, T., Salmon, E., Ivanoiu A., and Coyette, F. (2001). Acquisition of a novel vocabulary in an amnesic patient. Neurocase 7, 283-293.

Van der Linden, M., and Coyette, F. (1995). "Acquisition of word processing knowledge in an amnesic patient: Implications for theory and rehabilitation," in Broken Memories: Neuropsychological Case Studies, eds R. Campbell and M. Conway (Oxford: Blackwell), 54-80.

Van der Linden, M., Juillerat, A., and Adam, S. (2003). "Cognitive intervention," in The Clinical Management of Early Alzheimer's Disease, eds R. Mulligan, M. Van der Linden, and A. C. Juillerat (Mahwah, NJ: Erlbaum), 169-233.

Van der Linden, M., Meulemans, T., and Lorrain, D. (1994). Acquisition of new concepts by two amnesic patients. Cortex 30, 305-317.

Van der Linden, M., and Van der Kaa, M. (1989). "Reorganization therapy for memory impairments," in Cognitive Approaches in Neuropsychological Rehabilitation, eds X. Seron and G. Deloche (New York: Lawrence Erlbaum Associates), 105-158.

Warrington, E. K., and Weiskrantz, L. (1968). New method of testing longterm retention with special reference to amnesic patients. Nature 217, 972-974.

Warrington, E. K., and Weiskrantz, L. (1974). The effect of prior learning on subsequent retention in amnesic patients. Neuropsychologia 12 $419-428$.

Warrington, E. K., and Weiskrantz, L. (1978). Further analysis of the prior learning effect in amnesic patients. Neuropsychologia 16, 169-177.

Weiskrantz, L., and Warrington, E. K. (1979). Conditioning in amnesic patients. Neuropsychologia 17, 187-194.

Wilson, B. (2009). Memory Rehabilitation. Integrating Theory and Practice. New York: The Guilford Press.

Wilson, B. A. (1987). Rehabilitation of Memory. New York: The Guilford Press.

Wilson, B. A. (1992). "Memory therapy in practice," in Clinical Management of Memory Problems, eds B. A. Wilson and N. Moffat (London: Chapman \& Hall), 121-153.

Wilson, B. A., Emslie, H. C., Quirk, K., and Evans, J. J. (2001). Reducing everyday memory and planning problems by means of a paging system: a randomised control crossover study. J. Neurol. Neurosurg. Psychiatr. 70, 477-482.

Wilson, B. A., Evans, J. J., Emslie, H., and Malinek, V. (1997a). Evaluation of NeuroPage: a new memory aid. I. Neurol. Neurosurg. Psychiatr. 63 113-115.

Wilson, B.A.,J.C., and Hughes, E. (1997b). Coping with amnesia: the natural history of a compensatory memory system. Neuropsychol. Rehabil. 7, 43-56.

Wilson, B. A., and Moffat, N. (1992). Clinical Management of Memory Problems. London: Chapman \& Hall.

Woodruff-Pak, D. S. (1993). Eyeblink classical conditioning in H.M.: delay and trace paradigms. Behav. Neurosci. 107, 911-925. 
Zangwill, O. L. (1966). "The amnesic syndrome," in Amnesia, eds C. W. M. Whitty and O. L. Zangwill (London: Butterworths), 77-91.

Conflict of Interest Statement: The authors declare that the research was con- ducted in the absence of any commercial or financial relationships that could be construed as a potential conflict of interest.

Received: 12 April 2010; paper pending published: 31 May 2010; accepted: 22 June 2010; published online: 14 July 2010.
Citation: Ptak R, Van der Linden $M$ and Schnider A (2010) Cognitive rehabilitation of episodic memory disorders: from theory to practice. Front. Hum. Neurosci. 4:57. doi: 10.3389/fnhum.2010.00057

Copyright (c) 2010 Ptak, Van der Linden and Schnider. This is an open-access article subject to an exclusive license agreement between the authors and the Frontiers Research Foundation, which permits unrestricted use, distribution, and reproduction in any medium, provided the original authors and source are credited. 